\title{
Vertical Urbanism: Re-conceptualizing the Compact City
}

ZHONGJIE LIN

University of North Carolina at Charlotte

Although the term "compact city" appears frequently in academic accounts on sustainable urbanism as well as in professional descriptions of planning projects, it is often used in a general manner to indicate such ideas as high density, mixed uses, walkability, and transit oriented development, all linking to the common principles of New Urbanism. Unfortunately this misses some important points, as the concept of compact city possesses the power to generate dynamic urban forms, utilize cutting-edge technologies, address pressing environmental issues, and respond to distinctive geographical and cultural contexts, thus challenging conventional notions of Urbanism. The awareness of the limitations of the current practice leads to the introduction of Vertical Urbanism as an alternative discourse on the compact city responding proactively to the state of contemporary metropolises characterized by density, complexity, and verticality. The reinvented concept of Vertical Urbanism moves away from the Modernist notion promoting tall buildings as dominant urban typology to explore physically interactive and socially engaged forms addressing the city as a multi-layered and multi-dimensioned organism. Informed by complex systems ranging from underground mass transit to futuristic ecology of vertical urban farm, this experimental urban design approach envisions a holistic organization of infrastructure, space, and ecology in a three-dimensional framework.

This paper derives from a series of urban design research studios under the common theme of Vertical Urbanism conducted in four different cities in the United States and China during 2010-2014 and recently shifted to Rio de Janeiro in Brazil. These studios took on various sites and design questions such as urban infrastructure, transit system, and urban waterfront redevelopments, testing the concept in different geographic and cultural settings. Sensitivity to locality in both ecological and cultural terms was emphasized across these studios although the schemes often engaged speculative and innovative modes of design production. This paper examines a number of issues around the urban design approach of Vertical Urbanism, including the drive for density and vitality, the relationship between horizontal and vertical dimensions, space of flow and scalar shift, as well as ecological and social adaptability of megaforms; but above all, it tries to explore the capacity of global urban tactics in providing localized design solutions.

\section{DEBATES ON THE COMPACT CITY}

The compact city is a relatively recent concept in the discourse of urbanism. Many attribute the idea to Jane Jacobs and her seminal work The Death and Life of Great American Cities, which argues strongly for dense and diverse urban centers like Manhattan over the neatly planned Modernist City or Garden City; but it was not until the late 1980s that the term Compact City became commonly used academically and professionally. ${ }^{1}$ This has to do with rising global awareness of sustainable development following the Brundtland Report in 1987, which prompted policy makers as well as professionals to rethink the role of urban design and development to better protect and sustain the human habitat. ${ }^{2}$ The discussion on the compact city routed through the policy circle to influence design, and was particularly well received in Europe with political leaders more concerned about issues pertaining to energy shortages, global warming, and the negative impacts of urban sprawl. Michael Breheny's 1992 essay documented the early debates on this concept and its implication in planning. ${ }^{3}$ Two governmental documents were particularly notable, both published in 1990. One is the United Kingdom's White Paper on the Environment entitled This Common Inheritance. ${ }^{4}$ The other is the Green Paper on the Urban Environment published by the Commission of the European Communities. ${ }^{5}$ Both recognize the role 
of the urban form and planning in achieving environmental and urban sustainability, and advocate the 'compact city' as a solution to the problems. ${ }^{6}$ The Green Paper went further to promote the compact city not solely for environmental benefits in energy consumption and emissions but also based on improving the quality of life. These documents were quite influential and led to a series of other publications in line with the idea. One such report that is probably also best known was put together by the Urban Task Force in the United Kingdoms led by Sir Richard Rogers in 1999 called Towards an urban Renaissance. ${ }^{7}$

However there have been constant debates on the idea of compact city. On the one hand, advocates claim the compact and functionally mixed urban form could solve neatly the two major urban problems - the desire to protect the natural environment and to preserve the quality of life that a healthy city provides. On the other hand, opponents have pointed out several limitations of the concept. Some critics suspect that the relationship between compact urban form and environmental improvement might not be as direct as the planner would like. Others suggest that the compact city has always been based on the European tradition, often referring to particular mediaeval or early modern urban forms in Europe, and thus representing certain fixed cultural identity. ${ }^{8}$ Although most recognize a compact form contribute positively to urban sustainability, the criticisms nevertheless indicate inadequacies of the prevailing notion of compact city.

Since the 1990s, New Urbanism has become a dominant discourse in city building and influenced practices across the world. As the two concepts share many principles like high density, mixed uses, walkability, and transit oriented development, the compact city has been often associated with the New Urbanism, further strengthening its connotation of traditional Western urban form. However, political, social and cultural factors have led to different forms of urban density in different societies. Thus the compact city as both a morphological, as well as sociological, concept should be interpreted in regional contexts when applied in urban design practice. Furthermore, the expanding territory of human agglomeration has led to a growing scale of contemporary urban systems, including its mass transportation, information network, and ecological system, which in turn are changing the process of urban intensification. It thus requires a reinterpretation of compactness in which a higher degree of urban integration becomes the key.

\section{CONCEPT OF VERTICAL URBANISM}

It was based on the observations noted above that we began to explore the concept of Vertical Urbanism. We focus on the dimension of "verticality" to study the concept city because it possesses the power to generate dynamic urban forms and utilize cutting-edge technologies, and is thus able to provide new insights into the current environmental issues of the city and challenge the conventional notions of urbanism. We used the advanced urban design studio as a laboratory to explore the concept and methods of Vertical Urbanism. The study has last several years, and is being developed into a publication.
Vertical Urbanism addresses design issues of urban areas of significant intensity supported by complicated urban systems that the conventional planning regulations and approaches are only able to manage inadequately. When urban density reaches a certain point and a city is dominated by a vertical dimension, all components of urban design including circulation, land uses, open spaces, ecological network, and human activities are distributed in a different pattern and their relationships mutate. As we can see in some of the world's mega-cities like Hong Kong, Shanghai, Tokyo, Seoul, and New York, the floor area to plot ratios can go above 1:12 and their residential densities can exceed 400 persons per acre. With such intensity, the planning area is no longer the surface but the entire built-up area and the potential buildable vertical space above. In such cities, transportation, programs, and open spaces are highly integrated in a system that stretches from underground to the top of buildings. We can no longer focus on the planning of the land, but should examine the city as a three-dimensional matrix for urban design solutions.

It is worth repeating that the verticality highlighted in this approach not only deals with the areas going upward from the ground; it involves looking beneath the land for underground transportation, service, and uses, as well as their relationship to the uses and structures above ground. Those areas around any major interchange metro station in cities like Tokyo and Shanghai are the best examples for such vertical connections throughout height/depth. The multi-level underground spaces often integrate commercial development, public use, pedestrian circulation, and parking facilities with an inner-city or inter-city transportation node that connects to the public area and open spaces above.

Vertical Urbanism is not a new idea. Architect and planners have been dreaming of urban forms to address increasing density since more than a century ago. The illustrations of future New York by Richard Rummell and other artists in the 1900s and 1910s envisaged a multilayer city of skyscrapers connected by interconnected bridges and serviced by automobile and rail transportation networks on different levels above and underground. ${ }^{9}$ These early-20th-century visions of the city as a machine have by now fallen out of favor, but the question remains relevant: can we design urban environment of high intensity which is efficient, sustainable, and livable, with the amenity,

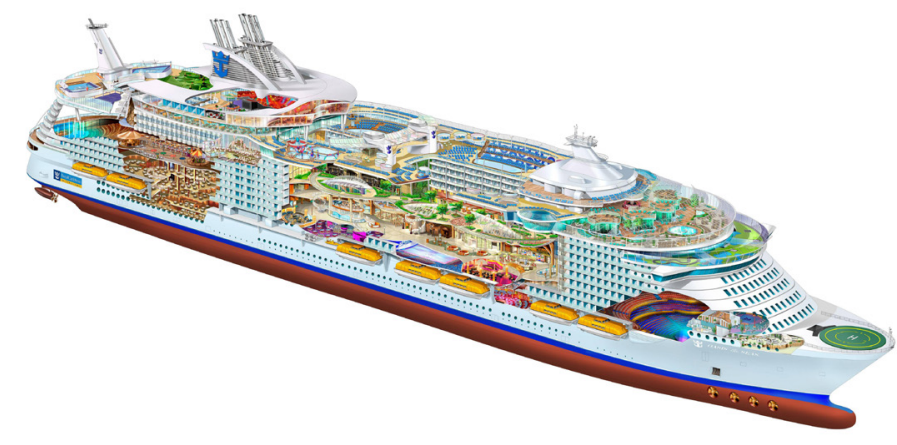

Figure 1: The world's biggest cruise ship Oasis of the Seas. 
landscape, and life style that we enjoy on the ground? The imperative and imminence have only been heightened as cities have become larger and contemporary urban systems more sophisticated.

The mid-20th Century witnessed many attempts in practice - both pragmatic urban tactics and ambitious utopian schemes - to formalize such verticality in urban design. Minneapolis' skyway system inaugurated in the 1960s were one of such meaningful experiments despite its limited scope of intervention. It extended the pedestrian circulation and retail to the upper levels, created linkage of downtown buildings and improved public transit. There were also numerous design projects, often associated with the Megastructure movements, advocating radical concepts challenging the status quo and provoking new thinking of Vertical Urbanism. Arata Isozaki's City in the Air represented the long-lasting aspiration of freedom from land and the faith in the capacity of technology to help shape a self-contained vertical human habitat. ${ }^{10}$ Numerous concepts, including Paolo Soleri's Arcology, have followed this utopian tradition and continued to inspire contemporary practice. ${ }^{11}$

How does Vertical Urbanism distinguish itself from conventional approaches of planning? An important source of inspiration comes from some megastructures we have created. The ocean liners, some of which can carry more than 5,000 passagers with extensive amenities like a self-contained town, provide an excellent model for a vertical compact city. In a large cruise ship, almost all programs we see in a small city, including housing/lodging, retail, dining, entertainment, gym, library/education, medical care, administration, and social space are packed into an extremely compact volume supported by an exceedingly efficient circulation system to serve a population range equivalent to a mid-size township. The compactness of such a "city" also significantly reduces energy consumption and carbon emission. Not necessarily resembling the ocean liner in form, many contemporary mega-projects, some involving a couple of blocks, have resorted to a similar integrative approach of planning. One example is the CCTV Headquarters complex design by the Office of Metropolitan Architecture, which illustrated the spatial organization of this giant building as a three-dimensional city.

The expanding territory of urban ecology and landscape represents another important dimension of the urban system calling for vertical urbanism. Projects like the High Line in New York have inspired the design strategy of "vertical park," making landscape an evolving system to allow the city grow and transform itself. The rising practice of vertical farming further indicates the promise of reconnecting highdensity urban centers back to the nature. Futuristic designs like the project called "Urban Epicenter/NYC" try to use vertical farming as a new urban program to rebalance environmental as well as social ecologies by putting agricultural production, housing, and social spaces adjacent to each other on different levels of the tower to maximize social interactions.

Finally, it is critical to differentiate the Vertical Urbanism from the vertical city. Skyscrapers dominate many urban centers and new Central Business Districts across the world. They are, however, vertical cities planned and built in the traditional manner and often characterized by the layout of "towers in the park" under Le Corbusier's influence. In contrast, Vertical Urbanism is less a static form than a dynamic strategy of urban design and development seeking a synthetic solution. In fact, the concept of Vertical Urbanism is intended to move away from the Modernist notion promoting tall buildings as dominant urban typology in order to explore physically interactive and socially engaged forms of the city and to address the city as a multilayered and multi-dimensioned organism. Such strategy is informed by contemporary systems ranging from underground mass transit to the futuristic urban farm, and aims for a holistic organization of infrastructure, space, and ecology in a three-dimensional framework. Density, complexity, and verticality are three keywords to

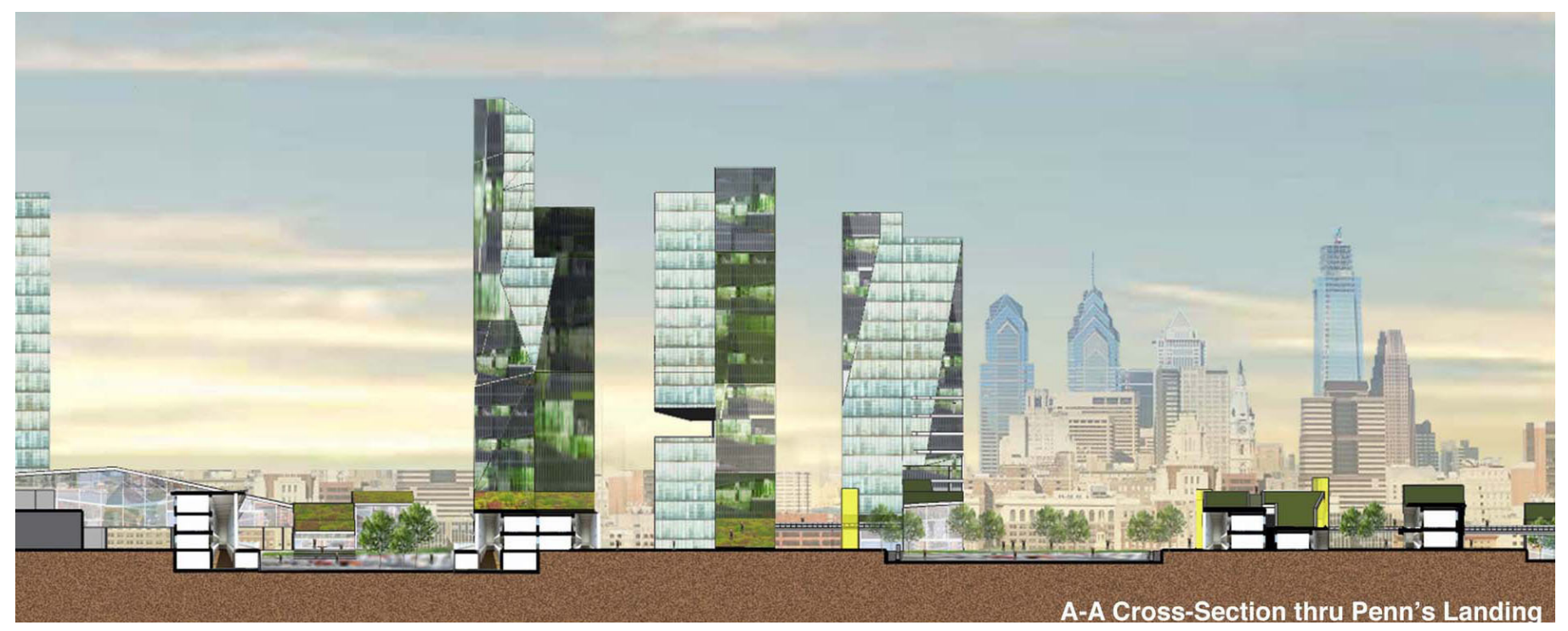

Figure 2: Redevelopment of Delaware Waterfront in Center City Philadelphia, 2011 
describe the characteristics of Vertical Urbanism. Density means the concentration of population, built area, and the intensity of social interaction. Complexity refers to the multiple and interconnected urban systems that form the backbone of the operation of a contemporary metropolis. Verticality indicates the multi-dimensional spatial network responding to such density and complexity to provide urban environment that is efficient, sustainable, and socially engaging.

\section{VERTICAL URBANISM STUDIOS}

Based on the notion of Vertical Urbanism, we participate in the debate on the contemporary forms of compact city. Although large-scale urban systems are characteristic of mega-cities across the globe, their impact on urban form must be analyzed within the local economic and cultural contexts. Since 2010, we have conducted a series of advanced urban design studios under the common theme of Vertical Urbanism for five years and in four different cities in the United States and China. Recently it was moved to South America and further developed in Rio de Janeiro. These studios used a variety of sites and focused on specific design questions including the regenesis of the urban highway, business district centered at a transit hub, revitalization of the historic downtown, and urban waterfront redevelopments, and test the concept in different geographic and cultural settings. Sensitivity to locality in both ecological and cultural terms was emphasized across the years although students were always encouraged to engage in speculative and innovative design thinking in the projects.

The 2011 studio consisted of two assignments. In the first phase, students participated in the Ed Bacon competition to rethink Philadelphia's I-95/CSX Corridor, anticipating the demolition of the highway in several years. Based on the competition entries, students continued to develop urban design schemes for the central waterfront area around Penn's Landing. The theme of competition "Intersect" represents a major challenge facing urban infrastructure built in the postwar decades. The transformation of central cities into the postindustrial era demands new notions of mobility and connectivity centered within an emerging ecological culture.

The challenge in this particular project was to reinterpret density, redesign the waterfront and tie it to the central business district and historic neighborhoods both physically and culturally. This task inspired the action of weaving the horizontal as well as vertical elements of the urban system. Soft ecological systems replaced the hard transportation structure to provide the backbone of programs and open spaces, overcoming the fracture created by the artery and significant grade change, and fostering ecological and social interaction.

In 2012, we started a three-year series of China summer program with the advanced studio built-in. The 2012 studio took place in Suzhou and studied the redevelopment of an industrial area into a business district which is adjacent to a recently completed high-speed rail station and will soon house a station for two metro lines. The extremely complex transportation networks and interchanges - highway and rail, inner-city and inter-city, elevated, surface, and underground - demand sophisticated three-dimensional design to provide a sensible solution.

Such complexity prompted students to pursue a higher-degree integration of programs, circulations, and spaces while conceiving consistent, legible, and elegant forms. Some teams used a parametric approach to envision an interactive relationship between building massing and open spaces and between the programs and circulation systems, breaking away from the traditional composition of isolated and repetitive towers and podiums. A park located at the center of the district would serve as the point of convergence of human activities and provide an escape to a man-made nature in the form of a "valley." Canals, an essential element of landscape in the historic city of Suzhou, were reintroduced, linking this area to its larger context and providing another layer of urban ecology.

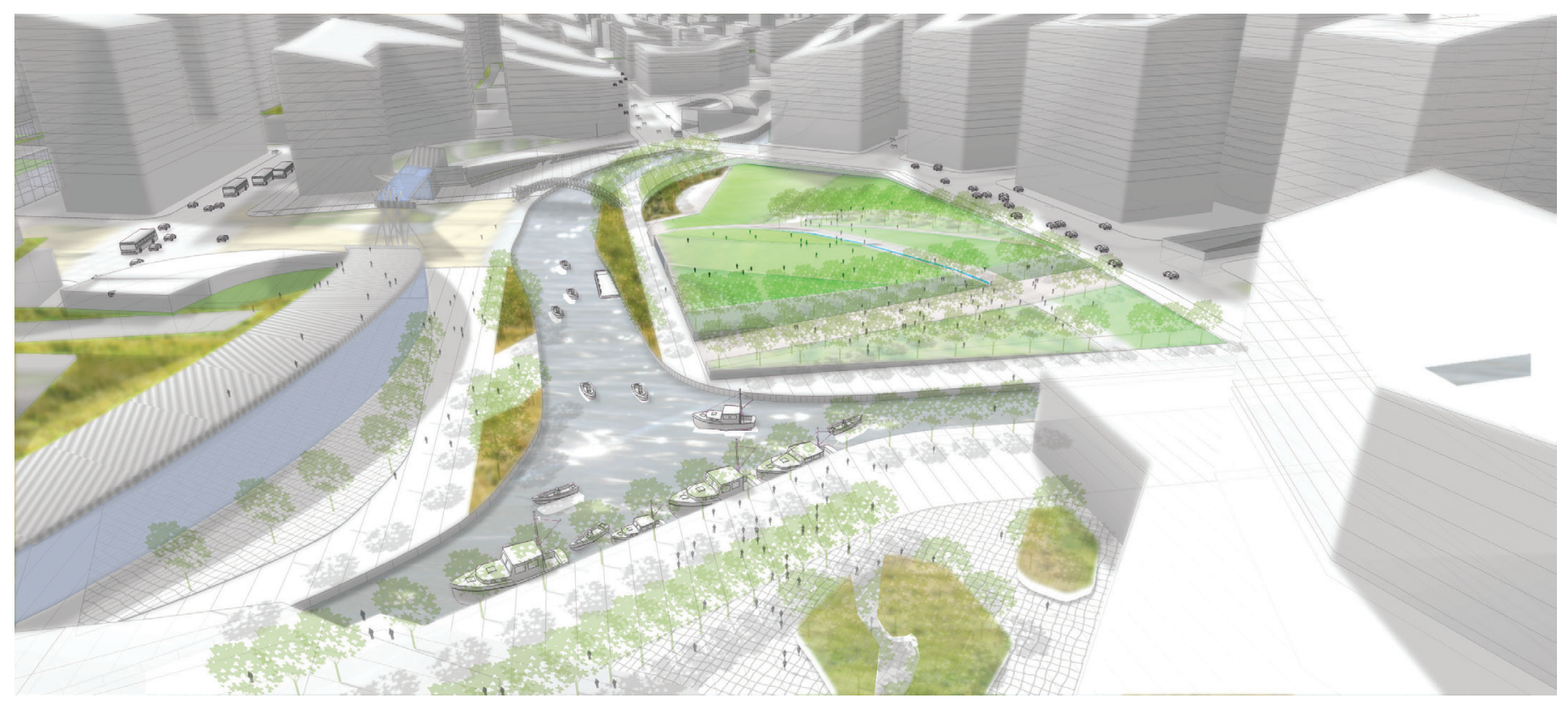

Figure 3: "Melding": Suzhou SIP high-speed Rail Station Area Redevelopment, 2012 


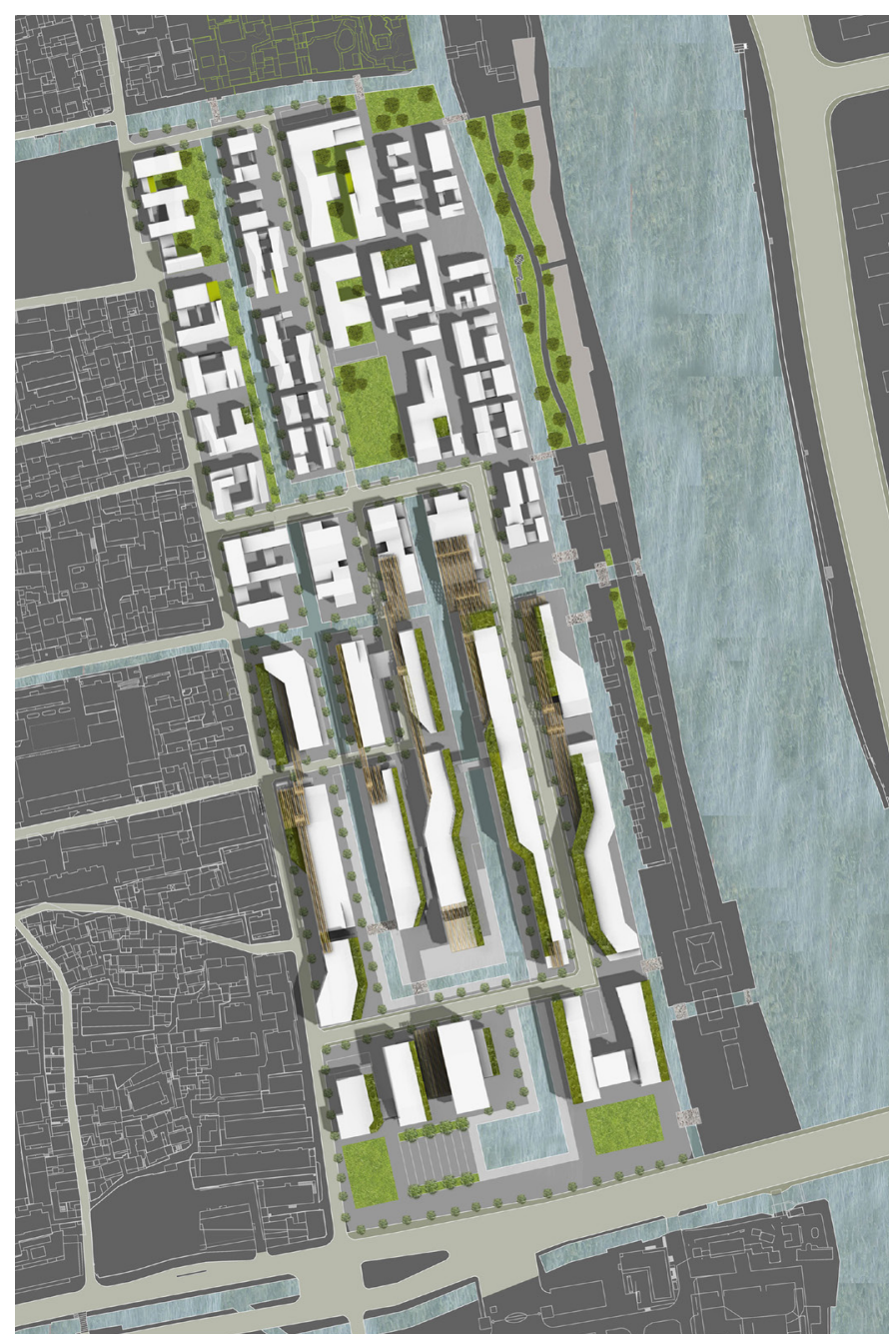

Figure 4: "Ribbons": Suzhou Xiangmen Block Redevelopment, 2013

The 2013 studio remained in Suzhou and turned out to be a nice demonstration of the concept of Vertical Urbanism that is different from a vertical city. The historic center of Suzhou is mostly flat - most buildings are two- or three-story - because a strict height limit is implemented to protect the city's numerous cultural sites including temples and the world-famous classical Chinese gardens (UNESCO World Heritage). The studied site is located within the old city wall. The complexity of programs and landscapes can be seen from the section of one of the student projects, showing the moat, the rebuilt city gate, the garden and historic buildings around the site, and a mix of proposed new programs and amenities aimed to revitalize the district including park, museum, retail, and housing. In addition, a new metro station is located at the southwest corner of the site.

The relationship, or contradiction, between vertical urbanism and horizontal landscape inspired students to seek alternative solutions to bring contemporary urbanity and maintain local identity without relying on traditional formal vocabulary. For example, the project called "Ribbon" consists of a series of horizontal ground-scrapers. It tries to reinterpret the pattern of paralleled strips of houses, narrow streets, and canals that are characteristic of the urban landscape of old Suzhou. Like the traditional approach, verticality is not considered as macro-scale urban structures, but rather micro-scale tactics mediating the canal, street, square, and buildings.

The discussion of the city as an integration of natural and cultural landscapes continued into the 2014 studio, which took place in the southern coastal city of Xiamen and looked at an area along the manmade Wuyuan Bay. The addition of new infrastructure including two metro lines and the relocation of the city's airport have made Wuyuan Bay a new urban node desirable for large-scale development. The studio sought an alternative model of development other than the stereotyped "towers in the park" and residential superblock.

The teams were inspired by the Zhongzhai village adjacent to the site, which originated as a minority tribal land but recently grew into a "village in the city": almost all peasants have turned their little cottages into seven-story towers with several apartment units to be leased to migrant workers; these illegal constructions occupy the entire plot, leaving only a few feet for tiny alleyways between buildings and buildings and resulting in unusual desnity. The plans for the 18-hectare new development looked for a middle ground between "megastructure" and "group form" according to Fumihiko Maki's terminology for collective forms. ${ }^{12}$ The resultant form indicated the organization of several clusters of modular buildings, combined the influence of the village-in-the-city's pattern of incremental construction on one hand, and the visual and regulatory order brought about by the large-scale infrastructure and landscape on the other - a solution that could only be achieved by a holistic approach of the urban system as a changing network.

\section{CONCLUSION: DENSITY, COMPLEXITY, AND VERTICALITY}

The study of the compact city has evolved along with the rising awareness of climate change and the changing notion of sustainable development. However, the debates around this concept over the decades reveal some constraint of the prevailing definition and application linking it to the specific traditional European urban form. Vertical Urbanism argues for an alternative notion of the compact city. While we are still in the search of its paradigm, it becomes evident, through the various case studies, that vertical urbanism is not simply a high-density urban form or an image of skyscraper city. Rather it inspires us as a combinatory system responding to the nature of a contemporary metropolis as interacting layers of space, ecology, and information, which lead to an integrative design strategy for urban centers. ${ }^{13}$

The interrelationships between density, complexity, and verticality constitute the web of feedback loops influencing the forms of the compact city. The notion of Vertical Urbanism as a flexible design strategy instead of a static form suggests its adaptability to contemporary urban conditions in different geographic and cultural contexts. It applies more commonly in Asian cities, as these case studies indicate, and sometimes almost looks like an Asian model because of the dynamic transformation of cities in this region and their emphasis in new urban infrastructure to stimulate urban development. These cities are in a critical stage of development to search for a sustainable 


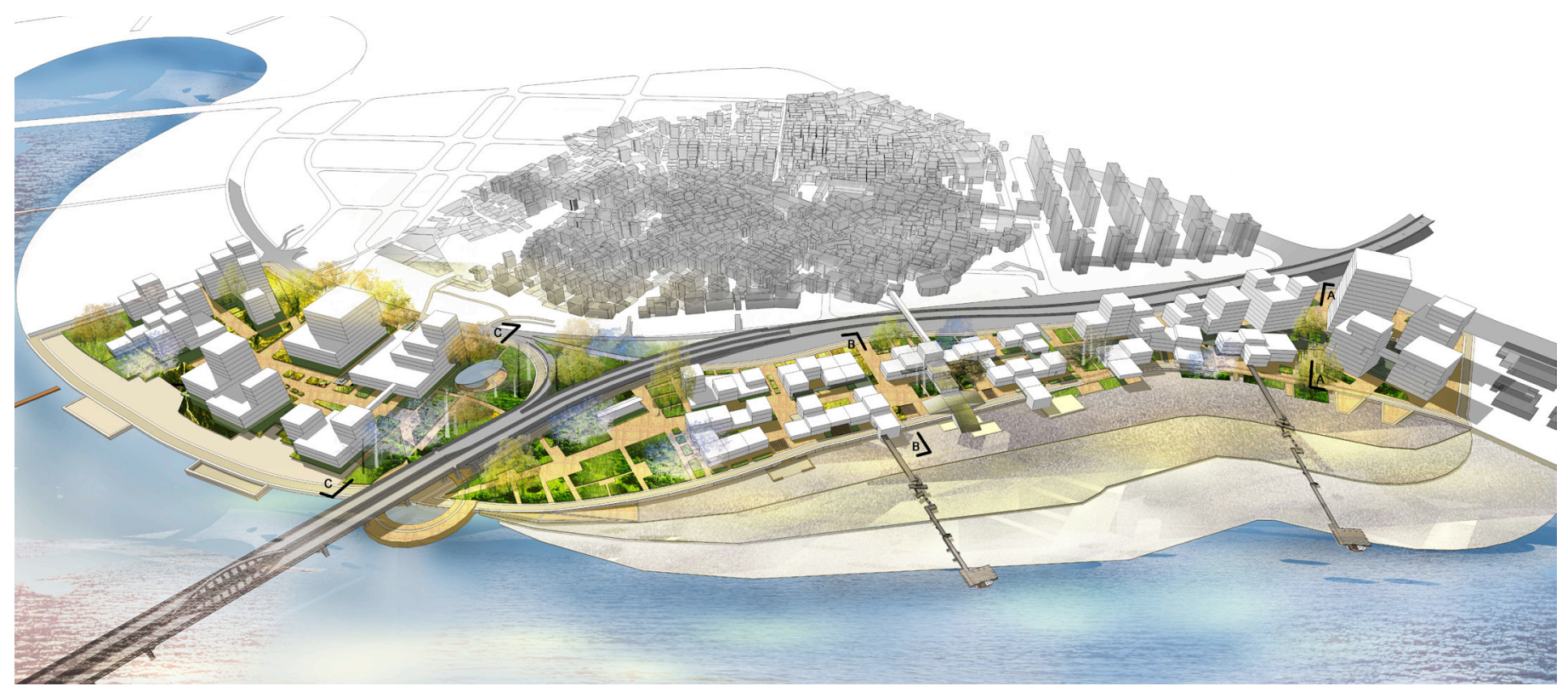

Figure 5: “Life between Blocks": Wuyuan Bay Redevelopment, 2014

path of building and define their identity of urban landscape, in which vertical urbanism should play an important role to influence the process.

\section{ENDNOTES}

1. Jane Jacobs, The Death and Life of Great American Cities (New York: Random House, 1961). There are some other early sources of the compact city including: Paul Goodman and Percival Goodman, Communitas: Means of Livelihood and Ways of Life (Chicago: University of Chicago Press, 1947); and George Dantzig and Thomas Saaty, Compact City: A Plan for a Livable Urban Environment (San Francisco: W H Freeman, 1973).

2. The World Commission on Environment and Development, "The Report of the World Commission on Environment and Development: Our Common Future," UN Documents, 1987.

3. Michael Breheny, "The Contradictions of the Compact City: A Review," in Michael Breheny ed. Sustainable Development and Urban Form (London: Pion, 1992), 138-159.

4. The UK Secretary of State for Environment et al, This Common Inheritance: Britain's Environmental Strategy (London: HMSO Publications, 1990).

5. Commission of the European Communities, Green Paper on the Urban Environment [COM(90) 218], 1990.

6. There are a few other important writings advocating the compact city and helping to articulate this concept, including Tim Elkin et al, Reviving the City: Towards Sustainable Urban Development (London: Friends of the Earth, 1991); and Harley Sherlock, Cities are Good for Us (London: Walkden House, 1990).

7. Urban Task Force, Towards an urban Renaissance (London: Routledge, 1999).

8. Breheny, 156

9. 09_Endnotes. Clita accusata corrumpit eos at, animal imperdiet ei vim. Bonorum volumus nostrum eam ne, est erat tempor dissentiunt eu. Eu usu.

10. For details of Arata Isozaki's work and discussion of megastructure, see Zhongjie Lin, Kenzo Tange and the Metabolist Movement: Urban Utopias of Modern Japan (London: Routledge, 2010).

11. Paolo Soleri, Arcology, the City in the Image of Man (Cambridge: MIT Press, 1969).

12. Fumihiko Maki, Investigations in Collective Form (St. Louis: Washington University in St. Louis, 1964).

13. There are some shared idea between the vertical urbanism and the combinatory urbanism that Thom Mayne advocates. Thom Mayne, Combinatory Urbanism: A Realignment of Complex Behavior and Collective Form (Los Angeles: Stray Dog Café, 2011). 